Article

\title{
Natural Sesquiterpene Lactones of the 4,15-iso-Atriplicolide Type are Inhibitors of Trypanothione Reductase
}

\author{
Mairin Lenz ${ }^{1}$, R. Luise Krauth-Siegel ${ }^{2}$ and Thomas J. Schmidt ${ }^{1, *(D)}$ \\ 1 Institute of Pharmaceutical Biology and Phytochemistry (IPBP), University of Münster, PharmaCampus \\ Corrensstraße 48, D-48149 Münster, Germany; m_lenz01@uni-muenster.de \\ 2 Biochemie-Zentrum der Universität Heidelberg (BZH), Im Neuenheimer Feld 328, D-69120 Heidelberg, \\ Germany; luise.krauth-siegel@bzh.uni-heidelberg.de \\ * Correspondence: thomschm@uni-muenster.de; Tel.: +49-251-83-33378
}

Received: 30 September 2019; Accepted: 11 October 2019; Published: 16 October 2019

\begin{abstract}
In the course of our investigations on the antitrypanosomal potential of sesquiterpene lactones (STL), we have recently reported on the exceptionally strong activity of 4,15-iso-Atriplicolide tiglate, which demonstrated an $\mathrm{IC}_{50}$ value of $15 \mathrm{nM}$ against Trypanosoma brucei rhodesiense, the etiologic agent responsible for East African human trypanosomiasis (HAT). Since STLs are known to often interact with their biological targets (e.g., in anti-inflammatory and anti-tumor activity) by means of the covalent modification of biological nucleophiles-most prominently free cysteine thiol groups in proteins-it was a straightforward assumption that such compounds might interfere with the trypanothione-associated detoxification system of trypanosomes. This system heavily relies on thiol groups in the form of the dithiol trypanothione $\left(\mathrm{T}(\mathrm{SH})_{2}\right)$ and in the active centers of enzymes involved in trypanothione metabolism and homeostasis. Indeed, we found in the present study that 4,15-iso-atriplicolide tiglate, as well as its structural homologues, the corresponding methacrylate and isobutyrate, are inhibitors of trypanothione reductase (TR), the enzyme serving the parasites to keep $\mathrm{T}(\mathrm{SH})_{2}$ in the dithiol state. The TR inhibitory activity was demonstrated to be time-dependent and irreversible. Quite interestingly, of the several further STLs with different core structures that were also tested, none inhibited TR at a significant level. Thus, the TR inhibitory effect by the 4,15-iso-atriplicolide esters appears to be specific for this particular type of furanoheliangolide-type STL. Some structure-activity relationships can already be deduced on the basis of the data reported here, which may serve as the starting point for searching further, possibly more potent, TR inhibitors.
\end{abstract}

Keywords: sesquiterpene lactone; 4,15-iso-atriplicolide ester; Trypanosoma brucei; Trypanosoma cruzi; trypanothione reductase; irreversible inhibitor; antitrypanosomal activity

\section{Introduction}

Sesquiterpene lactones (STLs) have, in many cases, been found to possess antiprotozoal activity. African trypanosomes (Trypanosoma brucei spp.), responsible for human African trypanosomiasis (HAT) appear to be particularly sensitive to some STLs [1-3]. Thus, the first compound of this class ever reported as a trypanocidal agent, helenalin, possesses an in vitro $\mathrm{IC}_{50}$ value of only $50 \mathrm{nM}$ against T. brucei rhodesiense (Tbr, causing East African HAT) [4] and still ranges among the most active STLs against this parasites. More recently, we discovered several STLs of the furanoheliangolide type as potent trypanocides, namely, budlein A, goyazensolide and, most importantly, 4,15-iso-Atriplicolide tiglate [2] with $\mathrm{IC}_{50}$ values in a similar range or even lower than that of helenalin. The latter compound displayed an $\mathrm{IC}_{50}$ value of only $15 \mathrm{nM}$, and is currently the STL with the strongest anti-Tbr activity 
discovered so far. Its methacryalate and isobutyrate analogues were more recently found to be only a little less active against this parasite [5]. Sesquiterpene lactones exert many of their biological activities by means of Michael-type additions of their reactive structure elements (mostly enone systems such as $\alpha, \beta$-unsaturated lactone and ketone structures) to nucleophilic groups of their biological targets. Free cysteine thiol groups are most prominently affected by such modifications. Therefore, it was straightforward, already in our very first report on antitrypanosomal activity of STLs [4], to hypothesize that the activity of such compounds against the parasites under study might be due to interference with the trypanosomes' peculiar intracellular thiol, trypanothione, and the associated enzymatic pathways needed for redox homeostasis and the detoxification of reactive species.

Unlike other eukaryotes, trypanosomatids use the bis-glutathionyl spermidine trypanothione $\mathrm{T}(\mathrm{SH})_{2}$ to maintain redox homeostasis and also for the detoxification of electrophilic xenobiotics. To maintain $\mathrm{T}(\mathrm{SH})_{2}$ in the reduced state, they utilize the enzyme trypanothione reductase (TR), which is parasite-specific and thus a potential drug target [6,7].

After the initial finding that helenalin is a potent antitrypanosomal agent, the compound was tested for a possible inhibitory activity on TR but was found to be inactive [8]. The recent discovery of furanoheliangolides with strong antitrypanosomal activity $[2,5]$ renewed our interest in components of the trypanothione system as possible targets of such compounds. Therefore, such compounds as well as some representatives of other STL types with proven activity against Tbr were investigated for potential activity against TR.

\section{Results and Discussion}

2.1. Activity of Antitrypanosomal STLs against Trypanothione Reductase from Trypanosoma brucei (TbTR) and T. $\operatorname{cruzi}(\mathrm{TcTR})$

The antitrypanosomal activity of the STLs under study (structures shown in Figure 1) has been published previously. With $\mathrm{IC}_{50}$ values $<0.1 \mu \mathrm{M}$, the iso-atriplicolide esters $\mathbf{1}$ and $\mathbf{2}$ [2,5], goyazensolide 4, and budlein A 5 [2], as well as the helenanolide 6 [1] are among the most active STLs against T. brucei rhodesisense found so far. The other compounds, 3 [5], 7 [1], and 8 [2] also showed considerable activity against this parasite. All compounds were less active against $T$. cruzi, but still showed significant activity $[1,2,5]$. In order to obtain insights into their possible mechanism of action, their activity against trypanosomal trypanothione reductases (TR) was tested.



$\mathrm{R}$

1 tiglate

2 methacrylate

3 isobutyrate

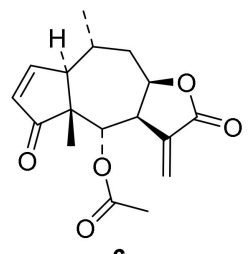

6

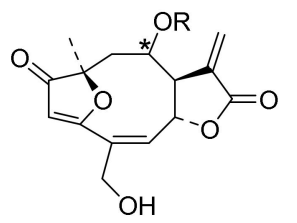

$\mathrm{R}$

4 methacrylate $(\alpha) 8 S$

5 angelate $(\beta) \quad 8 R$

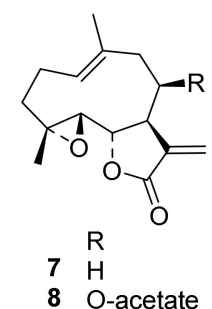

Figure 1. Chemical structures of the sesquiterpene lactones (STLs) tested in this study.

All the selected STLs mentioned above were submitted to inhibitory studies on recombinant TR from both T. brucei (TbTR) as well as T. cruzi (TcTR). The latter is structurally very similar to the enzyme 
of $T$. brucei $(\mathrm{Tb})$ with $83 \%$ identical residues overall and $100 \%$ identity of the amino acids of the active site [9], so that it was included in order to test for possible differences in susceptibility. All compounds were tested against both enzymes at a concentration of $100 \mu \mathrm{M}$. The readout of the TR assay [10] is NADPH consumption measured by the decrease of absorption at $340 \mathrm{~nm}$. The results are reported in Table 1.

Table 1. In vitro activity of selected STLs (structures see Figure 1) against recombinant trypanothione reductase from both T. brucei (TcTR) and T. cruzi (TbTR). In vitro activity data against T. brucei rhodesiense $(\mathrm{Tbr})$, T. cruzi $(\mathrm{Tc})$, and L6 rat skeletal myoblasts are from our previous reports $[1,2,5]$ and repeated here for easier comparison. Enzyme inhibition data represent mean \% inhibition at $100 \mu \mathrm{M} \pm \mathrm{SD}(n \geq 2)$.

\begin{tabular}{|c|c|c|c|c|c|c|c|c|}
\hline \multirow[t]{3}{*}{ Compound } & \multirow[t]{3}{*}{$T b r$} & \multirow{3}{*}{$\begin{array}{c}T c \\
\mathrm{C}_{50}(\mu \mathrm{M})\end{array}$} & \multirow[t]{3}{*}{$L 6$} & \multicolumn{2}{|c|}{ TcTR } & \multicolumn{3}{|c|}{ TbTR } \\
\hline & & & & \multicolumn{5}{|c|}{$\begin{array}{l}\% \text { Inhibition at } c=100 \mu M \\
\text { Preincubation Time }(\mathrm{min})\end{array}$} \\
\hline & & & & 0 & 15 & 0 & 15 & 30 \\
\hline 1 & 0.015 & 3.7 & 1.2 & $42 \pm 0$ & $89 \pm 1$ & $39 \pm 3$ & $87 \pm 1$ & $92 \pm 0$ \\
\hline 2 & 0.077 & 1.6 & 0.52 & $0 \pm 0$ & $41 \pm 1$ & $6.0 \pm 2.4$ & $68 \pm 1$ & $84 \pm 0$ \\
\hline 3 & 0.26 & 3.1 & 0.88 & $33 \pm 2$ & $80 \pm 0$ & $8.0 \pm 2.8$ & $62 \pm 1$ & $79 \pm 0$ \\
\hline 4 & 0.073 & 1.1 & 0.49 & n.i. & n.t. & n.t. & n.t. & n.i. \\
\hline 5 & 0.072 & 1.8 & 0.38 & $5 \pm 8$ & n.t. & n.t. & n.t. & $3 \pm 3$ \\
\hline 6 & 0.063 & 0.54 & 0.81 & n.i. & n.t. & n.t. & n.t. & n. i ${ }^{*}$ \\
\hline 7 & 0.39 & 11 & 7.2 & n.i. & n.t. & n.t. & n.t. & $2 \pm 8$ \\
\hline 8 & 0.23 & 11 & 4.7 & n.i. & n.t. & n.t. & n.t. & n.i. \\
\hline
\end{tabular}

${ }^{*}$ no inhibition at $100 \mu \mathrm{M} ; 10 \pm 2 \%$ inhibition observed at $200 \mu \mathrm{M}$ of 6 ; n.i.: No inhibition. n.t.: Not tested.

Quite strikingly, only the iso-atriplicolide esters 1-3, but none of the other tested STLs, showed activity against either TR under the chosen conditions. Since it was expected that the STL inhibitors would act by a covalent (i.e., irreversible) modification of the enzyme, more detailed experiments were conducted with the structural analogues 1-3, comparing their effects at 40 and $100 \mu \mathrm{M}$ concentration without and with preincubation in the presence of NADPH for $15 \mathrm{~min}$ as well as $30 \mathrm{~min}$ in case of TbTR. The results are reported in Table 1 and plotted in Figure 2. Clearly, the degree of inhibition strongly increased in all cases with the preincubation time. Compound 1 turned out to be the most potent inhibitor. At $100 \mu \mathrm{M}$ and 15 min preincubation, it inhibited TbTR by $87 \%$ and TcTR by $89 \%$ of the enzyme activity. All three compounds displayed a time- and concentration-dependent inhibitory activity on both TbTR and TcTR; however, these showed some differences in sensitivity. While the tiglate $\mathbf{1}$ is the most active inhibitor in both cases, it is noteworthy that the methacrylate $\mathbf{2}$ is a more potent inhibitor of TbTR than the isobutyrate 3, whereas it was vice versa in the case of TcTR. The two enzymes share a highly conserved active site in which all residues making direct contact with the substrate are identical. Nevertheless, some differences exist that should account for the different susceptibility to inhibitors, which has previously been described for other inhibitors [11].

On the backdrop that all tested compounds are rather potent trypanocides and share the possibility of forming covalent bonds with their potential target proteins, it appears rather noteworthy that none of the other compounds (4-8) showed any measurable effect on either TR at the chosen concentration. Even the strong trypanocide helenalin acetate (6) was found to be essentially inactive against both TRs. At $200 \mu \mathrm{M}$ and after 30 min preincubation, 6 caused only a minute inhibition of TbTR of about $10 \%$. Similarly, neither of the other furanoheliangolides $(4,5)$ or germacranolides $(7,8)$ at $100 \mu \mathrm{M}$ showed any significant effects on TcTR and TbTR (neither without nor with preincubation for 30 min), thus confirming that the inhibitory activity on TR is a unique feature of the iso-atriplicolides within the tested set of STLs. 
The time-dependence of the inhibitory effect of 1-3 gives a clear hint that the enzyme is indeed inhibited by an irreversible mechanism.
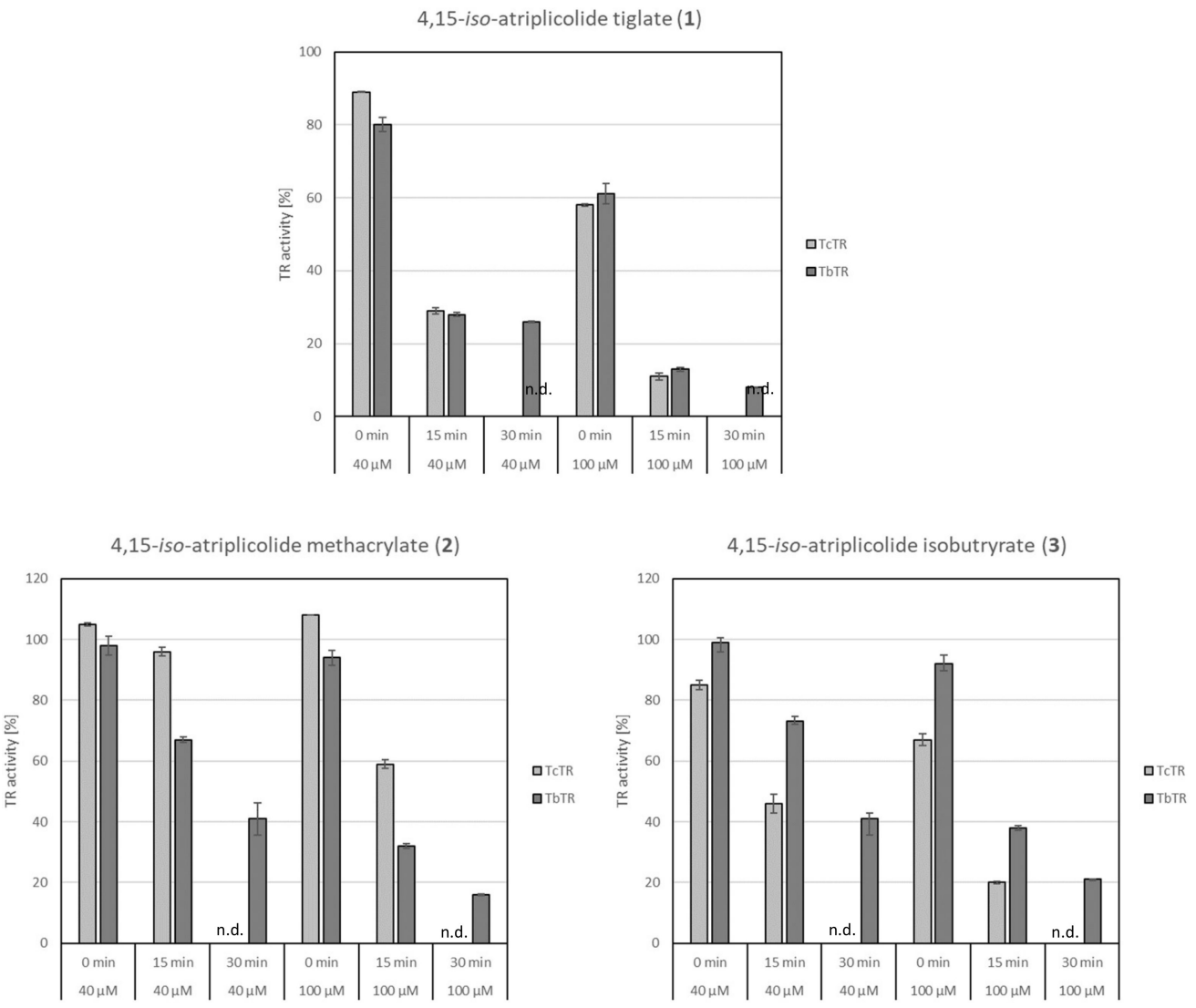

Figure 2. Inhibition of TR by STLs 1-3 in the presence of NADPH. Diagrams show the relative activity (\% residual activity in relation to untreated controls) of TcTR and TbTR after the addition of each STL at the specified concentration and preincubation for the specified time. n.d.: Inhibition of TcTR after 30 min preincubation was not determined.

\subsection{Mode of Inhibition of TbTR by 4,15-iso-Atriplicolide Esters}

The time-dependence of the 4,15-iso-atriplicolides' inhibitory effect on TR already indicated that these STLs act by the covalent modification of the enzyme. In order to prove that this is indeed the case, experiments were conducted with 1 , the strongest inhibitor. TbTR was preincubated with the compound in the presence/absence of NAPDH. After certain time intervals up to $3 \mathrm{~h}, 5-\mu \mathrm{L}$ aliquots were taken, and the remaining activity was determined in a standard assay. In case of a reversible inhibitor, the inhibitory effect would be strongly diminished or even lost under these conditions, due to the 200-fold dilution of the inhibitor in the assay. Moreover, there should be no increase of the inhibitory effect over time. The results are shown in Figure 3. 


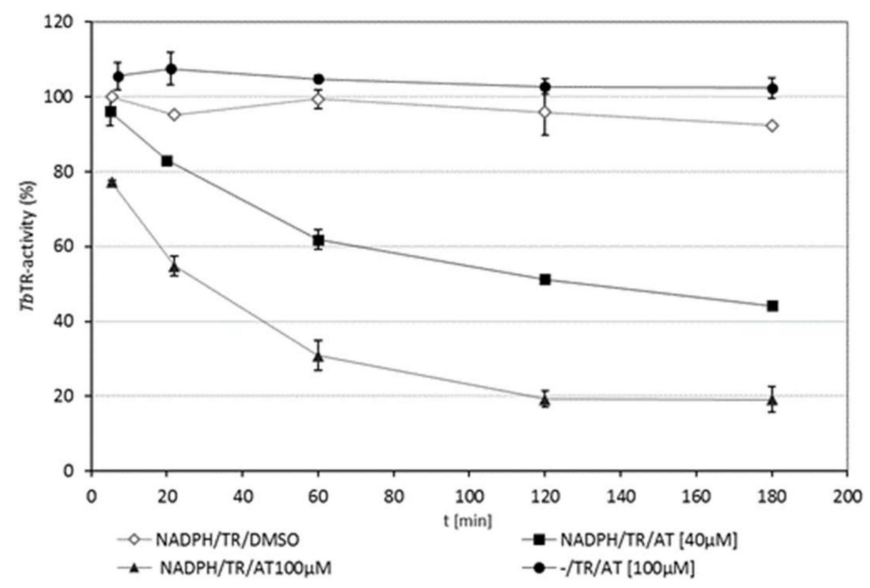

Figure 3. Time-dependent inhibition of TbTR by STL 1 (AT). The solvent (blank control, open diamond) or the STL (40 [filled square] and $100 \mu \mathrm{M}$ [filled triangle]) was incubated with TR in the presence of NADPH; the STL was also incubated with TR in the absence of NADPH (filled circle). Samples were taken at the different time points, and the remaining activity was measured in a standard TR assay containing $100 \mu \mathrm{M}$ NADPH and $100 \mu \mathrm{M}$ TS 2 (data represent the averages of two independent determinations \pm deviations from the mean).

It becomes evident that the inhibitory effect, also after 200-fold dilution of the aliquot used for each assay, increases over time and follows an exponential trend that is well in line with (pseudo) first-order kinetics, as expected for a chemical reaction between the enzyme and inhibitor under the chosen conditions with a high excess of inhibitors $(40$ and $100 \mu \mathrm{M})$ over enzymes $(1.23 \mu \mathrm{M})$. The two curves also clearly show the concentration-dependence of the inhibitory activity. Analogous experiments were conducted with the congeneric esters 2 and 3, which behaved in essentially the same manner (see Supplementary Figure S1).

\subsection{TbTR is Only Inhibited by 4,15-iso-Atriplicolide Esters in its Reduced Dithiol State}

The active site of TR contains a redox active dithiol/disulfide couple (Cys 52 and 57). Upon the binding of NADPH to TR, the disulfide bridge is reduced, and Cys52 directly reacts with the oxidized trypanothione [7]. As Cys52 has been shown to be the target of a variety of irreversible inhibitors [12-14], it was straightforward to expect that this thiol group is the actual target of the Michael-type addition with the iso-atriplicolides. As can be seen in Figure 3 (filled circles), in the absence of NADPH, the enzyme indeed retains its full activity. This strongly suggests that Cys 52 is the target site for covalent modification by $\mathbf{1}$; the same was found in analogous experiments with compounds 2 and 3 (Supplementary Figure S1).

\subsection{Kinetics of Inhibition of TbTR by 4,15-Iso-Atriplicolide Esters}

To further characterize the mode of inhibition, the activity of TR was measured as a function of substrate concentration, in the absence and presence of 40 and $80 \mu \mathrm{M}$ of 1 . The Lineweaver-Burk plot (i.e., $1 / \mathrm{v}_{0}$ versus $1 /[\mathrm{S}]$, see Figure 4 ) showed an intersection of the three lines above the ordinate. The apparent $\mathrm{Ki}$ and $\mathrm{Ki}^{\prime}$ values were determined as $128 \pm 8$ and $183 \pm 15 \mu \mathrm{M}$. 


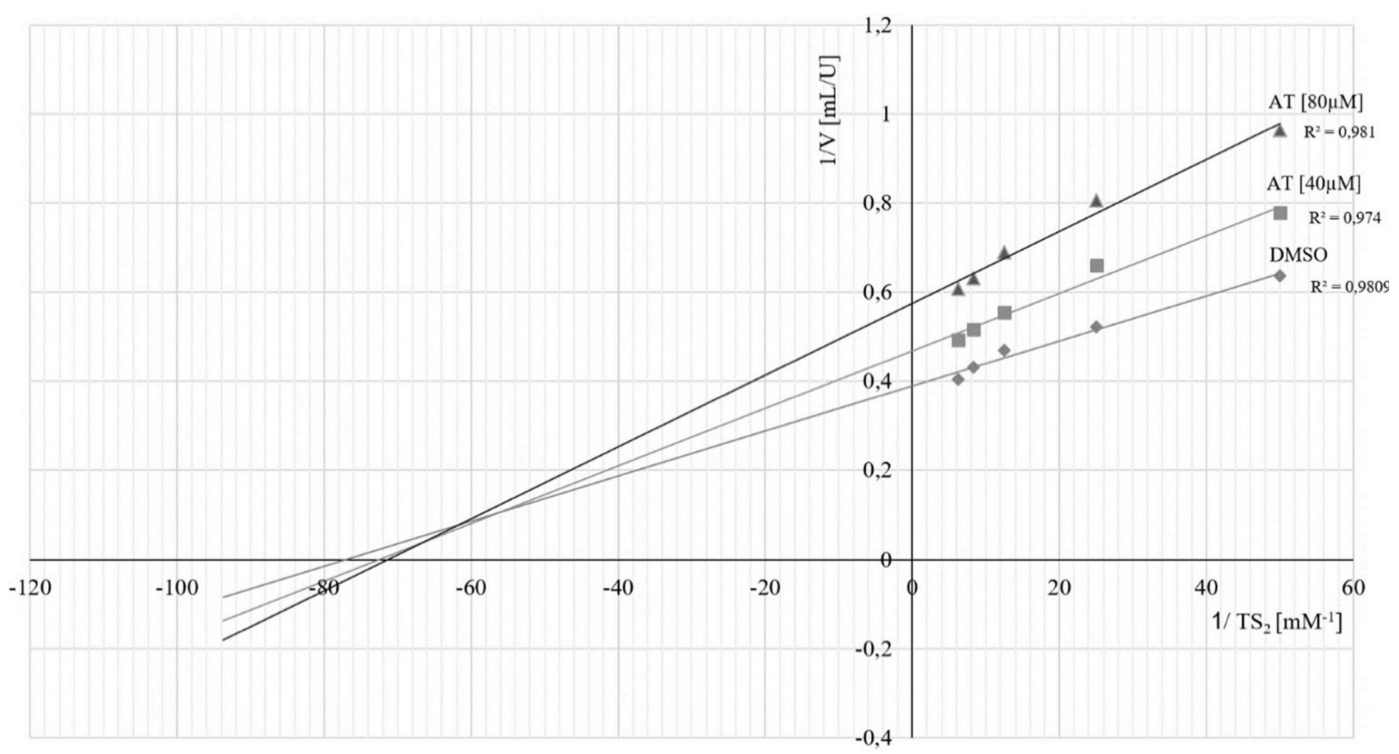

Figure 4. Lineweaver-Burk diagram for inhibition kinetics of compound 1 (AT) on TbTR.

This apparent mixed inhibition type indicates that the inhibitor binds more easily to the free enzyme than to the enzyme-substrate complex [15], which is likely in the present case, where the STL must bind to the free enzyme in order to deactivate it. In other words, the small increase of $K_{M}$ caused by an increasing concentration of $\mathbf{1}$ can be expected as a consequence of a (quite weak) competitive contribution to the overall inhibition. Such a competitive component should indeed exist, since the STL must first bind to the active site of the enzyme to form an initial, non-covalent complex, before the actual reaction occurs. In this process, it competes with the substrate, $\mathrm{TS}_{2}$, and it can also be displaced by increasing the substrate concentration from this initial complex, which straightforwardly explains the observed kinetics.

\section{Materials and Methods}

\subsection{Compounds under Study}

All compounds under study were previously described, and their antitrypanosomal activity was reported: 1, 4, 5, 8 [2], 2, 3 [5], 6, 7 [1].

\subsection{Enzmes}

TcTR and TbTR were purified from recombinant E. coli, as described previously [11].

\subsection{Enzyme Inhibition Assays}

Standard TR assay: The assay was carried out as described previously [10,11]. In short, to $1 \mathrm{~mL}$ of assay solution at pH 7.5 containing $40 \mathrm{mM}$ HEPES, $1 \mathrm{mM}$ EDTA, $100 \mu \mathrm{M}$ NADPH, and about $10 \mathrm{mU}$ TbTR or TcTR ( $5 \mu \mathrm{L}$ of a stock solution containing $2 \mathrm{U} / \mathrm{mL})$, the adequate volume of a $4-\mathrm{mM}$ stock solution of the test compound in DMSO was added to yield the final specified concentration of the test compound and a concentration of 5\% DMSO. 5\% DMSO served as blank control. The components were mixed in a photometric cuvette thermostated at $25^{\circ} \mathrm{C}$. The cuvette was either immediately (no preincubation) or after different times ( 15 or $30 \mathrm{~min}$ preincubation) inserted into the spectrophotometer at $25{ }^{\circ} \mathrm{C}$, and a baseline was recorded for $90 \mathrm{~s}$ at $\lambda=340 \mathrm{~nm}$. Then, the reaction was started by adding trypanothione disulfide $\left(\mathrm{TS}_{2}\right)$ [16] in a final concentration of $100 \mu \mathrm{M}$. Thus, both the substrate and cosubstrate were present at concentrations well above their respective $\mathrm{K}_{\mathrm{M}}$ values $(\approx 10$ and $\approx 1 \mu \mathrm{M}[10,17])$, ensuring that the assay was conducted under full enzyme saturation. The absorbance at $340 \mathrm{~nm}$ was monitored for at least $120 \mathrm{~s}$. The decrease in absorbance over time $(\Delta \mathrm{A} / \mathrm{min})$ was 
determined from the linear first $60 \mathrm{~s}$ of the time course. As a measure of enzyme activity, volume activity $\left(\mathrm{a}_{\mathrm{v}}[\mathrm{U} / \mathrm{mL}]\right)$ was determined as follows, using the millimolar absorbance coefficient of NADPH; $\varepsilon(\mathrm{NADPH})=6.2 \mathrm{mM}^{-1} \times \mathrm{cm}^{-1}$.

$$
a_{v}\left[\frac{U}{m L}\right]=\frac{\Delta A / \min }{\varepsilon(N A D P H) * d[\mathrm{~cm}]} \times \frac{\text { total assay volume }[\mathrm{mL}]}{\text { volume enzyme solution }[\mathrm{mL}]}
$$

Each data point (enzyme activity in the presence of test compound at a specified concentration) was measured at least twice. The percentage of inhibition as reported in Table 1 was then calculated as $100 \times(1-(a / b))$, where $a$ is $\mathrm{a}_{\mathrm{v}}$ in the presence of the test compound, and $b$ in the absence of the test compound.

The enzyme kinetics to determine the type of inhibition were performed under the same conditions at three different inhibitor concentrations: 0,40 , and $80 \mu \mathrm{M}$ (all with a DMSO concentration of 5\%). Assays were performed with five different concentrations of $\mathrm{TS}_{2}$ over the range of 20-160 $\mu \mathrm{M}(20$, $40,60,80,120$, and $160 \mu \mathrm{M})$. The resulting data were for volume activity were plotted in reciprocal form $(\mathrm{mL} / \mathrm{U})$ versus the reciprocal substrate concentration $\left(\left[\mathrm{TS}_{2}\right]^{-1}\left(\mu \mathrm{M}^{-1}\right)\right)$ to yield the plot presented in Figure 4. Inhibition constants ( $\mathrm{Ki}$ and $\mathrm{Ki}^{\prime}$ values) were determined from the slopes, and ordinate intercepts of the two data series were obtained in the presence of $\mathbf{1}$ [15].

A dilution assay to test for the irreversible inhibition of TbTR: In this case, $300 \mathrm{mU}$ TR were preincubated in a volume of $100 \mu \mathrm{L}$ with 40 or $100 \mu \mathrm{M}$ of the inhibitor in the presence or absence of $100 \mu \mathrm{M} \mathrm{NADPH}$ at $25^{\circ} \mathrm{C}$ for up to $3 \mathrm{~h}$. 5\% DMSO was used instead of the STL as blank control. At various time points $(5,20,60,120$, and $180 \mathrm{~min})$, aliquots of $5 \mu \mathrm{L}(15 \mathrm{mU}$ TR) were taken from the mixture and added into a standard TR assay. The assay was started by adding $100 \mu \mathrm{M} \mathrm{TS} 2$, the absorbance at $340 \mathrm{~nm}$ was monitored as above, and the enzyme activity was determined from $\Delta \mathrm{A} / \mathrm{min}$ as above. The resulting remaining activity was plotted versus time (min) in Figure 3.

\section{Conclusions}

The inhibitory activity of the 4,15-iso-atriplicolide esters on TR appears to be unique among the tested STLs, and hence cannot be a mere consequence of the presence of reactive Michael acceptor structures. The inactivity of two other furanoheliangolides, goyazensolide and budlein A, which are structurally very similar to the iso-atriplicolides, leads to the conclusion that the iso-atriplicolide scaffold with an exocyclic double bond between C-4 and C-15 enables these compounds to bind to the active center of TR in a specific manner. It can be speculated that this double bond, as part of an $\alpha, \beta, \gamma, \delta$-unsaturated keto function, is actually the reactive partial structure that leads to the covalent deactivation of the enzyme. It is interesting to note that the small differences in the ester moiety confer different potency to the compounds against the TRs of T. brucei and T. cruzi. Thus, this part of the molecules has a modulatory influence on activity, and it will be interesting to investigate further ester derivatives with the same basic skeleton to study the structure-activity relationships in more detail. On the background that several STLs of this study that previously were shown to have very strong antitrypanosomal activity were inactive against TR, it can safely be stated that TR inhibition can be ruled out as a general mechanism of action of STLs against T. brucei. This is in line with the previous results of our group as well as those of others $[8,18]$. The level of inhibitory potency of the iso-atriplicolide esters against TR is much too low to account-on its own-for these STLs' high-level antirypanosomal activity, for which other mechanisms must be held responsible. However, the discovery of the 4,15-iso-atriplicolide scaffold as a TR inhibitor opens the possibility to search for further, perhaps more potent, TR inhibitors with similar molecular characteristics.

Supplementary Materials: The following are available online, Figure S1: Time-dependent inhibition of TbTR by STLs 2 and 3. Analogous plot to Figure S3.

Author Contributions: T.J.S. and R.L.K.-S. conceived and initiated the study. R.L.K.-S. provided the enzymes and laboratory facilities in Heidelberg. T.J.S. supervised the experiments conducted in the Münster laboratory; M.L. 
isolated and identified the STLs from H. tuberosus, performed the studies, and evaluated the data. T.J.S. wrote the manuscript.

Funding: This research received no external funding.

Acknowledgments: The authors thank Natalie Dirdjaja, BZH, Heidelberg, for the preparation of the recombinant trypanothione reductases and trypanothione. This work was part of the activities of ResNetNPND (http: //www.ResNetNPND.org/) and of COST action CM1307. Coverage of the article processing charges for this publication by COST action CM1307 is gratefully acknowledged.

Conflicts of Interest: The authors declare no conflict of interest.

\section{References}

1. Schmidt, T.J.; Nour, A.M.M.; Khalid, S.A.; Kaiser, M.; Brun, R. Quantitative structure-Antiprotozoal activity relationships of sesquiterpene lactones. Molecules 2009, 14, 2062-2076. [CrossRef] [PubMed]

2. Schmidt, T.J.; Da Costa, F.B.F.; Lopes, N.P.N.; Kaiser, M.; Brun, R. In Silico prediction and experimental evaluation of furanoheliangolide sesquiterpene lactones as potent agents against Trypanosoma brucei rhodesiense. Antimicrob. Agents Chemother. 2014, 58, 325-332. [CrossRef] [PubMed]

3. Kimani, N.M.; Matasyoh, J.C.; Kaiser, M.; Nogueira, M.S.; Trossini, G.H.G.; Schmidt, T.J. Complementary quantitative structure-activity relationship models for the antitrypanosomal activity of sesquiterpene lactones. Int. J. Mol. Sci. 2018, 19, 3721. [CrossRef] [PubMed]

4. Schmidt, T.J.; Brun, R.; Willuhn, G.; Khalid, S.A. Anti-trypanosomal activity of helenalin and some structurally related sesquiterpene lactones. Planta Med. 2002, 68, 750-751. [CrossRef] [PubMed]

5. Galkina, A.; Krause, N.; Lenz, M.; Daniliuc, C.G.; Kaiser, M.; Schmidt, T.J. Antitrypanosomal activity of Sesquiterpene Lactones from Helianthus tuberosus L. including a new Furanoheliangolide with an unusual Structure. Molecules 2019, 24, 1068. [CrossRef] [PubMed]

6. Comini, M.; Flohé, L. Trypanothione-Based Redox Metabolism of Trypanosomatids. In Trypanosomatid Diseases Molecular Routes to Drug Discovery; Jäger, T., Koch, O., Flohé, L., Eds.; Wiley-VCH: Weinheim, Germany, 2013; pp. 167-199.

7. Leroux, A.E.; Krauth-Siegel, R.L. Thiol redox biology of trypanosomatids and potential targets for chemotherapy. Mol. Biochem. Parasitol. 2016, 206, 67-74. [CrossRef] [PubMed]

8. Schmidt, T.J. Structure-activity relationships of sesquiterpene lactones. In Studies in Natural Products Chemistry—Bioactive Natural Products (Part M); Ur Rahman, A., Ed.; Elsevier: Amsterdam, The Netherlands, 2006; pp. 309-392.

9. Patterson, S.; Alphey, M.S.; Jones, D.C.; Shanks, E.J.; Street, I.P.; Frearson, J.A.; Wyatt, P.G.; Gilbert, I.H.; Fairlamb, A.H. Dihydroquinazolines as a Novel Class of Trypanosoma brucei Trypanothione Reductase Inhibitors. Discovery, Synthesis, and Characterization of their Binding Mode by Protein Crystallography. J. Med. Chem. 2011, 54, 6514-6530. [CrossRef] [PubMed]

10. Jockers-Scherübl, M.C.; Schirmer, R.H.; Krauth-Siegel, R.L. Trypanothione reductase from Trypanosoma cruzi. Catalytic properties of the enzyme and inhibition studies with trypanocidal compounds. Eur. J. Biochem. 1989, 180, 267-272. [CrossRef] [PubMed]

11. Persch, E.; Bryson, S.; Todoroff, N.K.; Eberle, C.; Thelemann, J.; Dirdjaja, N.; Kaiser, M.; Weber, M.; Derbani, H.; Brun, R.M.; et al. Binding to Large Enzyme Pockets. Small-Molecule Inhibitors of Trypanothione Reductase. ChemMedChem 2014, 9, 1880-1891. [CrossRef] [PubMed]

12. Gallwitz, H.; Bonse, S.; Martinez-Cruz, A.; Schlichting, I.; Schumacher, K.; Krauth-Siegel, R.L. Ajoene is an Inhibitor and Subversive Substrate of Human Glutathione Reductase and Trypanosoma cruzi Trypanothione Reductase: Crystallographic, Kinetic, and Spectroscopic Studies. J. Med. Chem. 1999, 42, 364-372. [CrossRef] [PubMed]

13. Saravanamuthu, A.; Vickers, T.J.; Bond, C.S.; Peterson, M.R.; Hunter, W.N.; Fairlamb, A.H. Two Interacting Binding Sites for Quinacrine Derivatives in the Active Site of Trypanothione Reductase A template for drug design. J. Biol. Chem. 2004, 279, 29493-29500. [CrossRef] [PubMed]

14. Lee, B.; Bauer, H.; Melchers, J.; Ruppert, T.; Rattray, L.; Yardley, V.; Davioud-Charvet, E.; Krauth-Siegel, R.L. Irreversible Inactivation of Trypanothione Reductase by Unsaturated Mannich Bases: A Divinyl Ketone as Key Intermediate. J. Med. Chem. 2005, 48, 7400-7410. [CrossRef] [PubMed]

15. Bisswanger, H. Enzyme kinetics. Principles and Methods, 2nd ed.; Wiley-VCH: Weinheim, Germany, 2008. 
16. Comini, M.A.; Dirdjaja, N.; Kaschel, M.; Krauth-Siegel, R.L. Preparative enzymatic synthesis of trypanothione and trypanothione analogues. Int. J. Parasitol. 1999, 39, 1059-1062. [CrossRef] [PubMed]

17. Jones, D.C.; Ariza, A.; Chow, W.-H.A.; Oza, S.L.; Fairlamb, A.H. Comparative structural, kinetic and inhibitor studies of Trypanosoma brucei trypanothione reductase with T. cruzi. Mol. Biochem. Parasitol. 2010, 169, 12-19. [CrossRef] [PubMed]

18. Zimmermann, S.; Oufir, M.; Leroux, A.; Krauth-Siegel, R.L.; Becker, K.; Kaiser, M.; Brun, R.; Hamburger, M.; Adams, M. Cynaropicrin targets the trypanothione redox system in Trypanosoma brucei. Bioorg. Med. Chem. 2013, 21, 7202-7209. [CrossRef] [PubMed]

Sample Availability: Not available.

(C) 2019 by the authors. Licensee MDPI, Basel, Switzerland. This article is an open access article distributed under the terms and conditions of the Creative Commons Attribution (CC BY) license (http://creativecommons.org/licenses/by/4.0/). 